CEB Working Paper

\title{
Good Diversification is Never Wasted: How to Tilt Factor Portfolios with Sectors
}

\section{Marie Brière and Ariane Szafarz}

Using large-cap exchange-traded funds (ETFs), this paper provides guidance on enhancing the performance of long-only factor portfolios through sector-based blending. The blending method builds ETF portfolios that optimize the factor exposure of sectors. We use the original factors of Fama and French as benchmarks. The results show that blended portfolios combine the diversification benefits of sector investing with the risk premia of factor investing, and so constitute a promising extension of pure factor ETFs.

Keywords: Portfolio management, asset allocation, factor, industry, sector, crisis.

JEL Classifications: G11, C61, E44, G01.

CEB Working Paper N¹9/014

May 2019 


\title{
Good Diversification is Never Wasted: How to Tilt Factor Portfolios with Sectors
}

\author{
Marie Brière \\ Paris-Dauphine University and Amundi \\ 91, Boulevard Pasteur, 75015 Paris, France \\ Email: marie.briere@amundi.com \\ Phone +331763 39161
}

\author{
Ariane Szafarz \\ Université Libre de Bruxelles \\ Solvay Brussels School of Economics and Management, Centre Emile Bernheim \\ 50, Avenue F.D. Roosevelt, 1050 Brussels, Belgium \\ Email: aszafarz@ulb.ac.be \\ Phone +3326504865
}

This version: May 2019

\section{Forthcoming in Finance Research Letters}

Keywords: Portfolio management, asset allocation, factor, industry, sector, crisis JEL codes: G11, C61, E44, G01 


\title{
Good Diversification is Never Wasted: How to Tilt Factor Portfolios with Sectors
}

\begin{abstract}
Using large-cap exchange-traded funds (ETFs), this paper provides guidance on enhancing the performance of long-only factor portfolios through sector-based blending. The blending method builds ETF portfolios that optimize the factor exposure of sectors. We use the original factors of Fama and French as benchmarks. The results show that blended portfolios combine the diversification benefits of sector investing with the risk premia of factor investing, and so constitute a promising extension of pure factor ETFs.
\end{abstract}




\section{Introduction}

After Fama and French (F\&F) (1992) demonstrated the existence of factor-based premia, ${ }^{1}$ asset managers started developing factor investing techniques, including ETFs, with the aim of capturing these premia by holding assets with positive exposure to the F\&F factors (Ang, 2014). Yet, factor exposures turned out to be both difficult to replicate (Ang et al., 2009) and transaction-intensive (Frazzini et al., 2014), meaning that transaction costs could significantly hamper the financial performance of factor investing (Novy-Marx \& Velikov, 2016). These issues probably explain why only a few F\&F factors are available as ETFs.

Since few ETF factors are available, diversifying factor-based portfolios can be challenging. In this paper, we circumvent the problem by increasing the universe of ETF factor portfolios thanks to the portfolio blending method developed by Ghayur et al. (2018). Intuitively, blending composite sector portfolios consists in seasoning them with sector exposure, thus enhancing their diversification potential. Our results suggest that sector-blended factors manage to capture some of the diversification benefits of sectors while maintaining the premia associated with sector investing.

\section{Data and Methods}

The original F\&F factors are not easily replicable, ETFs are surrogate factors available to investors. A notable advantage of ETFs is that the factor rebalancing costs are incorporated in the market prices (Brown et al., 2010). In practice, however, duplicating sophisticated factor investing strategies with ETFs can be tedious. First, only a few F\&F factor indices-small, big, value,

\footnotetext{
${ }^{1}$ There is a debate about whether the factors correspond to the remuneration of risk, and hence be called "risk factors," or alternatively result from abnormal stock pricing, and then be referred to as "anomalies" (McLean, and Pontiff, 2016).
} 
growth, and high momentum- are available on the ETF market. Second, hardly any long-short ETFs exist, except for those shorting the market and some sectors. This further restricts risk reduction opportunities for portfolios made up of factor ETFs. ${ }^{2}$

To address the limitations of pure factor ETFs, we use sector ETFs. We adapt the blending method proposed by Ghayur et al. (2018) in order to build portfolios that optimally exploit the factor exposure of sectors. The approach is easy to implement since it requires only sector and factor ETFs, and therefore avoids the need to rebalance the stock composition of these indexes. To construct sector-blended factor replications and compare their performance with that of their original pure-factor benchmark, we proceed in two steps. First, Section 2.1 presents the data, which include both the original F\&F factors and liquid ETFs. Second, Section 2.2 explains how we constructed blended factor portfolios. To save space, we will restrict the approach to two factors (value and momentum), but extensions to multiple factors are straightforward. Value and momentum were chosen for their great popularity (Asness et al., 2013) testified by the high liquidity of the corresponding ETFs.

\subsection{ETF Market Data}

The ETF data were retrieved from the CRSP survivor-bias-free US mutual fund database. We filtered away manually non-US and non-equity ETFs and then selected the relevant ETFs based on their designation. We retained the value and momentum ETFs with the largest capitalization. Next, we chose ten sector ETFs based on the 11-sector GICS classification from which, like F\&F, we excluded real estate. The twelve ETFs we used are presented in Appendix A.

\footnotetext{
${ }^{2}$ While the option of shorting long-only ETFs is evoked in recent literature (Li \& Zhu, 2017), it is still far from standard. The feasibility and costs of shorting factor ETFs still deserve further investigation. See Cao et al. (2018) for more details on the smart-beta ETF market.
} 
Table 1: The 12 ETFs and their F\&F benchmarks: Descriptive Statistics - Jan 2013-Jun 2018

\begin{tabular}{cccccccc}
\hline ETF & $\begin{array}{c}\text { Net asset } \\
\text { value* }\end{array}$ & $\begin{array}{c}\text { First offer } \\
\text { date }\end{array}$ & $\begin{array}{c}\text { Annualized } \\
\text { return }\end{array}$ & Volatility & $\begin{array}{c}\text { F\&F } \\
\text { Benchmark }\end{array}$ & $\begin{array}{c}\text { F\&F ann. } \\
\text { return }\end{array}$ & $\begin{array}{c}\text { F\&F } \\
\text { volatility }\end{array}$ \\
\hline \hline Cons disc & 98.60 & $12 / 1998$ & 17.37 & 11.87 & Non dur & 11.27 & 10.28 \\
Cons stapl & 56.86 & $12 / 1998$ & 10.28 & 10.92 & Durable & 11.21 & 15.58 \\
Industrial & 147.29 & $06 / 2000$ & 14.37 & 11.51 & Manuf & 13.36 & 11.40 \\
Energy & 72.15 & $12 / 1998$ & 5.19 & 17.51 & Energy & 5.19 & 18.37 \\
Tech & 162.67 & $05 / 2000$ & 18.86 & 12.90 & Tech & 19.36 & 12.24 \\
Telecom & 29.39 & $05 / 2000$ & 10.43 & 11.72 & Telecom & 10.39 & 12.59 \\
Health & 174.12 & $06 / 2000$ & 15.94 & 12.19 & Health & 15.79 & 11.42 \\
Utilities & 132.88 & $06 / 2000$ & 11.88 & 13.29 & Utilities & 15.51 & 12.97 \\
Basic mat & 102.11 & $06 / 2000$ & 9.33 & 14.96 & Shops & 10.19 & 11.91 \\
Financials & 130.36 & $06 / 2000$ & 16.80 & 15.53 & Other & 15.84 & 12.17 \\
\hline & & \multicolumn{7}{c}{ Panel B: Factors } & & & \\
\hline Value & 114.08 & $05 / 2000$ & 12.07 & 10.01 & Value & 14.64 & 13.23 \\
Momentum & 114.07 & $10 / 2012$ & 14.64 & 9.75 & High mom & 16.11 & 11.68 \\
\hline
\end{tabular}

*in USD million at end 2017

We carried out the empirical analysis of ETF monthly returns on the longest available period, i.e. January 2013 to June 2018. In parallel, we duplicated the analysis on the same-period F\&F indices retrieved from Kenneth French's website. Table 1 displays the descriptive statistics for the ETFs and their F\&F benchmarks, while Figure 1 shows that both the value and momentum ETFs follow their F\&F benchmarks reasonably well, while slightly damping their volatility. This movement, particularly visible during 2016, could be due to the ETFs' managers wish to curtail transaction costs during periods of high volatility, implying frequent factor rebalancing. Over the sample period, the two factor ETFs were less volatile (the average volatility spread is $2.57 \%$ ) but also less profitable (the average annualized return spread is $2.02 \%$ ) than their F\&F benchmarks. 
Figure 1: Value and Momentum ETFs and Their F\&F Benchmarks - Jan 2013-Jun 2018
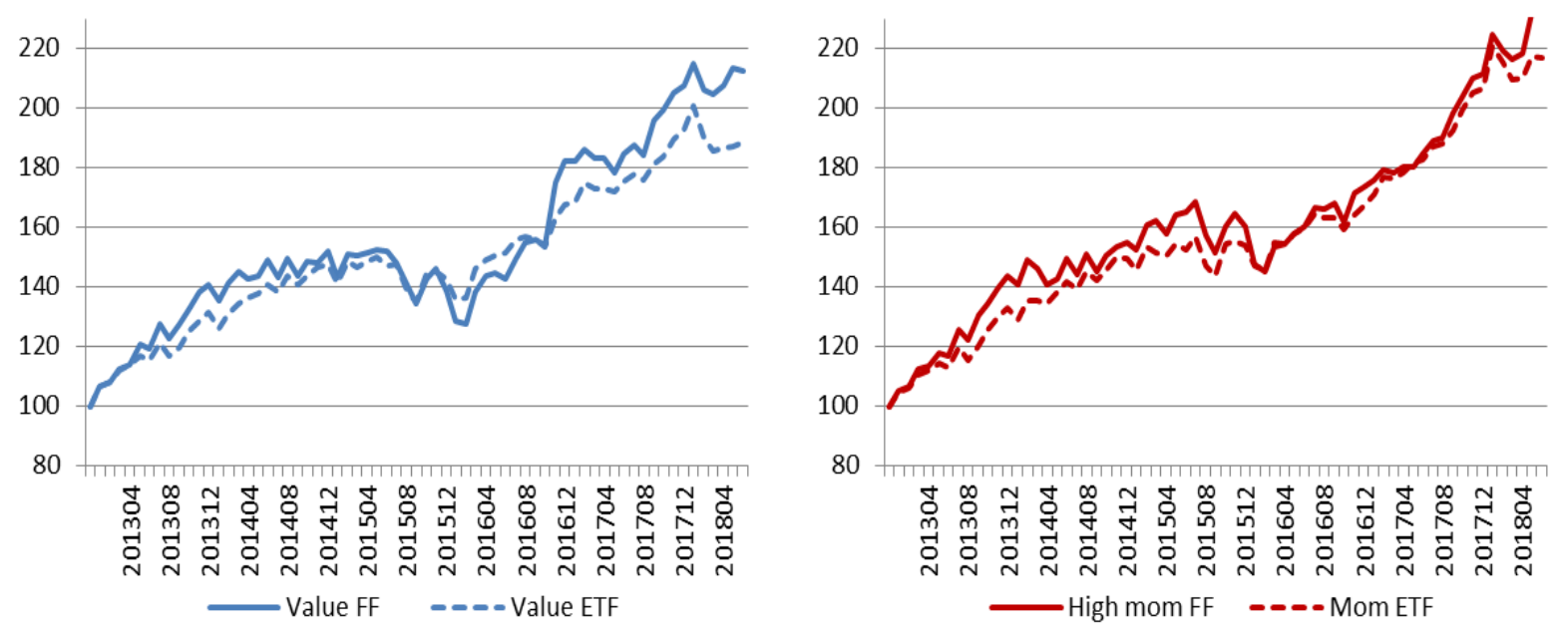

For sector ETFs, Table 1 delivers a less clear-cut picture: There is no systematic trend in the spreads between the ETFs and their F\&F benchmarks, in either the annualized return or the volatility statistics. Still, sector ETFs and the F\&F benchmarks move accordingly over the 20132018 period, with a remarkably profitable technological sector and a poorly performing, but very risky, energy sector.

\subsection{Sector-Blended Factor Portfolios}

Ghayur et al. (2018) construct long-only multifactor smart-beta strategies by combining either individual-factor signals (signal blending) or individual-factor portfolios (portfolio blending). The idea in both cases is to come up with a portfolio made up of securities selected for their exposure to target factors, thus building exposure-matched portfolios. Ghayur et al. (2018) compare the two blending methods and show that portfolio blending delivers higher information ratios for moderate levels of tracking error while signal blending performs better at high levels of tracking error.

To supplement factors with sector-based diversification, we use blending methods based on exposure matching. We adapt the two methods proposed by Ghayur et al. (2018) to build sector- 
blended factor portfolios and exploit sector ETFs to gain factor exposure at limited cost. In both cases, the ten sectors are first ordered according to the average z-score of their exposures to value and momentum. ${ }^{3}$ Then, for the signal blending method, we retain the top $50 \%$ of the universe, i.e. the five sectors with the highest average exposures to value and momentum. The resulting portfolio gives equal weight to the five selected sectors. By contrast, in the portfolio blending approach, the exposures to value and momentum are considered separately. The final equal-weight portfolio includes the three sectors with top exposures to value and the three sectors with top momentum exposure. Any sector that is "top" for both value and momentum has double weight in the portfolio composition.

\section{Empirical Results}

Blending is applied yearly to both the selected ETFs and their F\&F benchmarks. Table 2 shows the annualized returns, volatilities, alphas and Sharpe ratios, and the results of equality tests between sector-blended and pure factor portfolios. The performances of both types of blended portfolios are compared with those of their "pure factor" counterpart, equally divided between the value factor and the momentum factor.

To draw meaningful comparisons, we use bootstrap-based tests, which are often more appropriate to financial time-series than usual tests requiring Gaussian iid assumptions. Given the relatively short time-span covered by our data, we opted for a simple bootstrap approach (Ruiz \& Lorenzo, 2002). Most tests fail to detect significant results at the 5\% level. This again may be due to the short observation period. Yet, Table 2 provides insightful intuitions. First, the negative, but

\footnotetext{
${ }^{3}$ Exposures are measured with usual betas obtained from regressions including the risk-free rate and the excess market return, while z-scores are obtained by demeaning the corresponding betas and dividing the result by the standard deviation of the beta distribution.
} 
low, values of alpha obtained for the F\&F factors are attributable to the well-performing market in the very large F\&F universe of more than 4,000 stocks. Over the sample period, the return of the F\&F market index was $10.70 \%$. By contrast, the returns of its corresponding portfolio-blended and signal-blended alternatives were $8.26 \%$ and $9.42 \%$, respectively. Moreover, in the F\&F universe, signal blending produces optimal portfolios that are significantly less volatile than those obtained with its pure-factor counterpart.

The point estimates derived for the alphas and the SRs are well aligned, suggesting that both sector-based blending methods can outperform their pure factor benchmarks in the ETF universe, but not in the corresponding cost-blind F\&F framework. A possible interpretation is that exploiting the factor exposure of sectors is less expensive in terms of rebalancing costs than trading on individual stocks in a pure-factor perspective. Note that sector-blended ETF factors manage to surpass the already excellent Sharpe Ratio (equal to 1.00) obtained by the pure ETF factors. Figure 2 confirms visually that the two sector-blended factor portfolios outperform their pure-factor counterpart in the ETF universe but tend to underperform it during the second half of the sample period in the F\&F universe. Since only ETFs are readily investible and the F\&F factors are not, our findings bring good news to investors attracted by factor investing. 


\section{Table 2: Annualized Returns, Volatilities, Alphas and Sharpe Ratios}

This table reports the average return, volatility, alphas and Sharpe ratios of sector-blended factors and pure factor portfolios (value and momentum, equally weighted). The computation is run for both the F\&F and ETF factors. We provide the p-values of bootstrapped equality tests between the characteristics of blended and pure factor portfolios.

\begin{tabular}{|c|c|c|c|c|c|c|}
\hline Blending method & $\begin{array}{c}\text { Sector } \\
\text { blended FF } \\
\text { factors } \\
\end{array}$ & $\begin{array}{c}\text { Pure FF } \\
\text { factors }\end{array}$ & $\begin{array}{c}\text { Bootstrapped } \\
\text { p-value }\end{array}$ & $\begin{array}{c}\text { Sector } \\
\text { blended ETF } \\
\text { factors } \\
\end{array}$ & $\begin{array}{c}\text { Pure ETF } \\
\text { factors } \\
\end{array}$ & $\begin{array}{c}\text { Bootstrapped } \\
\text { p-value }\end{array}$ \\
\hline \multicolumn{7}{|c|}{ Ann. return ( $\mathrm{T}$ test $)$} \\
\hline Portfolio blend & $8.26 \%$ & \multirow{2}{*}{$10.70 \%$} & 0.26 & $11.14 \%$ & \multirow{2}{*}{$9.92 \%$} & 0.37 \\
\hline Signal blend & $9,47 \%$ & & 0.54 & $11.72 \%$ & & 0.26 \\
\hline \multicolumn{7}{|c|}{ Volatility (F test) } \\
\hline Portfolio blend & $11.97 \%$ & \multirow{2}{*}{$11.81 \%$} & 0.80 & $10.10 \%$ & \multirow{2}{*}{$9.53 \%$} & 0.17 \\
\hline Signal blend & $10,55 \%$ & & 0.05 & $10.47 \%$ & & 0.03 \\
\hline \multicolumn{7}{|c|}{ Alpha (Wald test) } \\
\hline Portfolio blend & -0.28 & \multirow{2}{*}{-0.09} & 0.42 & 0.08 & \multirow{2}{*}{0.00} & 0.59 \\
\hline Signal blend & -0.11 & & 0.94 & 0.10 & & 0.44 \\
\hline \multicolumn{7}{|c|}{ Sharpe Ratio (Ledoit and Wolf test) } \\
\hline Portfolio blend & 0.66 & \multirow{2}{*}{0.87} & 0.44 & 1.06 & \multirow{2}{*}{1.00} & 0.79 \\
\hline Signal blend & 0.86 & & 0.96 & 1.08 & & 0.64 \\
\hline
\end{tabular}

An additional rationale for our results is that sector-blended factors provide — at least partly-the diversification qualities of sector investing while maintaining the relevant factor exposure. If so, our findings would be consistent with those of papers showing that some factors exhibit redundancy (F\&F, 2015). Several explanations could help understand why sector investing is better than factor investing for diversifying risk away (Brière \& Szafarz, 2018). Sector-specific returns may involve more idiosyncratic risks than factor-specific returns. Factors alone combine typically more individual assets than do sectors alone. There can be a considerable amount of overlap between factor compositions, while overlaps between sectors are impossible by construction. All the sectors cover the whole investment universe of interest, while all the factors typically leave some stocks aside because they are built from quantiles of given characteristics.

Figure 2: Sector-Blended Factor Portfolios and Pure Factor Portfolios - Jan 2014-Jun 2018

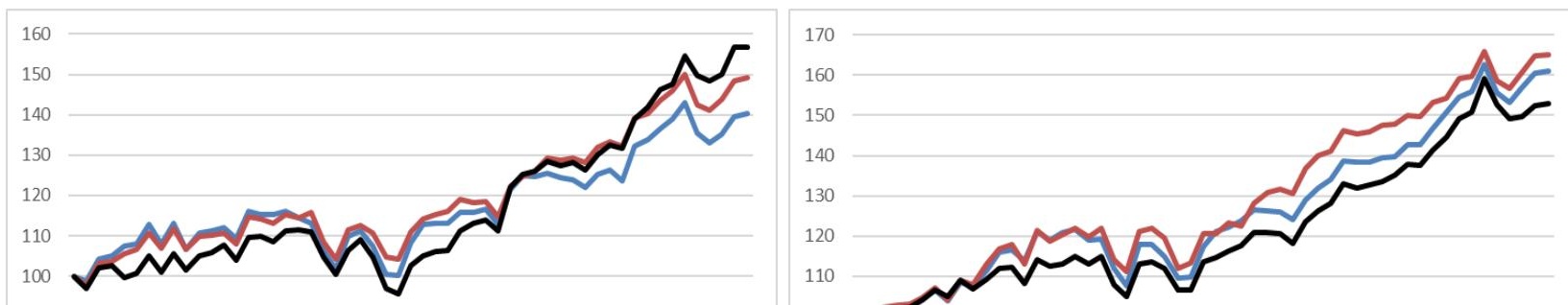


Sectors that trigger relevant factor-exposure are a promising field for building costconscious trading rules aiming at capturing the premia associated with factors. At the same time, thanks to the good diversification properties of sectors, refraining from trading individual stocks is almost costless. Although encouraging, our results are still preliminary. They call for a larger-scale empirical investigation on sector-blended factors built from ETFs.

\section{Conclusion}

The diversification potential of factor investing — or the lack of it—is still poorly understood (Sayili et al., 2017), while the diversification benefits brought by sector investing to same-country stock portfolios are well recognized (De Moor \& Sercu, 2011). This paper takes advantage of these facts to open promising opportunities for long-only investors. The trading rules we suggest are built with easy-to-implement blending techniques. Factor investing is often criticized for its high transaction costs, as opposed to more passive styles. This is why we use traded ETFs, whose returns incorporate rebalancing costs. From the standpoint of fund managers, factor-based portfolios require frequent, and therefore costly, rebalancing in individual stocks. Sector-blended factors circumvent the problem by limiting portfolio readjustments to annual sector-based rebalancing driven by sector exposure to the factors of interest (value and momentum in our exercise). The first, and still 
preliminary, results obtained show that sector-blended factor ETFs offer a valuable alternative to pure factor ETFs.

\section{References}

Ang, A. Asset Management - A Systematic Approach to Factor Investing. Oxford: Oxford University Press (2014).

Ang, A., W. Goetzmann, and S. Schaefer. "Evaluation of Active Management of the Norwegian GPFG.” Norway: Ministry of Finance (2009).

Asness, C.S., T. Moskowitz, and L. Pedersen. "Value and Momentum Everywhere." Journal of Finance, 68 (2013), 929-985.

Brière, M. and A. Szafarz. "Factors and Sectors in Asset Allocation: Stronger Together?" In Advances in the Practice of Public Investment Management: Portfolio Modelling, Performance Attribution and Governance, Basingstoke, UK: Palgrave Mcmillan (2018), 291-309.

Brown, S., A. Lynch, and A. Petajisto. "Hedge Funds, Mutual Funds, and ETFs." In Acharya, V., T.F. Cooley, M.P. Richardson and I. Walter (Eds.). Regulating Wall Street: The Dodd-Frank Act and the New Architecture of Global Finance, Hoboken, New Jersey: Wiley (2010), 351366.

Cao, J., J.C. Hsu, Z. Xiao, and X. Zhan. "Smart Beta, 'Smarter' Flows.” Available at SSRN: https://ssrn.com/abstract=2962479 (2018).

De Moor, L. and P. Sercu, "Country Versus Sector Factors in Equity Returns: The Roles of NonUnit Exposures," Journal of Empirical Finance, 18 (2011), 64-77.

Fama, E.F. and K.R. French. "The Cross-Section of Expected Stock Returns.” Journal of Finance, 47 (1992), 427-465. 
Fama, E.F. and K.R. French. "A Five-Factor Asset Pricing Model.” Journal of Financial Economics, 116 (2015), 1-22.

Frazzini, A., R. Israel, and T.J. Moskowitz. “Trading Costs of Asset Pricing Anomalies.” FamaMiller Working Paper, Chicago Booth Research Paper No.14-05 (2014).

Ghayur, K., R. Heaney, and S. Platt. “Constructing Long-Only Multifactor Strategies: Portfolio Blending vs. Signal Blending.” Financial Analysts Journal, 74 (2018), 70-85.

Li, F.W. and L.O. Zhu. "Short Selling ETFs." Hong Kong University of Science and Technology, Working Paper (2017).

Novy-Marx, R., and M. Velikov. “A Taxonomy of Anomalies and their Trading Cost.” Review of Financial Studies, 29 (2016), 104-147.

Ruiz, E., and P. Lorenzo. "Bootstrapping Financial Time Series.” Journal of Economic Surveys, 16(2002), 271-300.

Sayili, K., G. Yilmaz, D. Dyer, and A.M. Küllü, “Style Investing and Firm Innovation.” Journal of Financial Stability, 32 (2017), 17-29. 


\section{Appendix A: ETF Selection}

\section{Table A1: List of Selected ETFs}

\begin{tabular}{ll}
\hline ETF & \multicolumn{1}{l}{ ETF Name } \\
\hline \hline Panel A: Sectors \\
\hline Cons disc & Consumer Discretionary Select Sector SPDR Fund \\
Cons stapl & Consumer Staples Select Sector SPDR Fund \\
Indus & iShares US Industrials \\
Energy & Energy Select Sector SPDR Fund \\
Tech & iShares US Technology \\
Telecom & iShares US Telecommunications ETF \\
Health & iShares US Healthcare \\
Utilities & iShares US Utilities \\
Basic mat & iShares US Basic Materials \\
Financials & iShares US Financial Services \\
\hline Panel B: Factors \\
\hline Value & iShares S\&P 500 Value \\
High mom & SPDR S\&P 1500 Momentum TILT \\
\hline
\end{tabular}

